\title{
PENGARUH LIFE STYLE, SELF CONTROL DAN FINANCIAL LITERACY TERHADAP PERILAKU KONSUMTIF MAHASISWA MELAKUKAN ONLINE SHOPPING
}

\author{
Ratih Dewi Titisari Haryana \\ Sekolah Tinggi Urip Sumoharjo Surabaya \\ email: r.dewi017@gmail.com
}

\begin{abstract}
The development of technology is related to people's behavior in Indonesia. Indonesian people, especially the younger generation, are very fond of social media. Besides used to communicate, send emails, social media is also used to online shopping. This is evidenced by the growing number of marketplaces in Indonesia such as Bukalapak, Tokopedia, Shoppee, Lazada and the others. This study aims to determine the effect of life style, self control and financial literacy on consumptive behavior in online shopping. This research is a quantitative study using explanatory design. The sample used was FEB students in East Surabaya. Sample data that can be used are 102 respondents. The sampling technique uses convenience sampling. Data collection using questionnaire distribution techniques using multiple linear regression data analysis techniques. The results showed that life style had a positive and significant effect on consumer behavior in doing online shopping. While self control and financial literacy variables negatively and significantly affect consumer behavior in doing online shopping.
\end{abstract}

Keywords: life style, self control, financial literacy, consumptive behaviour

\section{PENDAHULUAN}

Perkembangan teknologi informasi yang berkembang begitu pesat, bahkan saat ini perkembangan tersebut mampu mempengaruhi gaya hidup masyarakat di Indonesia. Hal yang paling digemari dan disenangani oleh masyarakat adalah pemanfaatan sosial media. Tujuan dari hadirnya sosial media di tengah-tengah masyarakat adalah untuk mempermudah komunikasi dan berbagai kegiatan lainnya. Misalnya saja, temanteman yang dulunya tidak saling berkomunikasi sebelumnya akan terhubung kembali melalui sosial media, baik teman yang jauh (luar kota atau bahkan luar pulau) ataupun teman yang dekat (dalam satu kota). Sayangnya, kemudahan yang didapatkan melalui sosial media justru tidak sesuai dengan yang diharapkan. Nyatanya sekarang ini telah banyak ditemukan seseorang yang lebih asyik dengan gadget atau akun di dunia maya daripada berinteraksi sosial di dunia nyata. "Mendekatkan yang jauh, Menjauhkan yang dekat" begitulah kesimpulannya. Berdasarkan data survey yang telah dilakukan APJII (Asosiasi Penyelenggara Jasa Internet Indonesia) pada tahun 2018 tentang alasan utama individu dalam menggunakan internet menyimpulkan bahwa sebesar 18,9 \% masyarakat di Indonesia memanfaatkan internet untuk bersosial media. Alasan tersebut menempati urutan kedua dari 22 alasan yang lain. Sebanyak $41,2 \%$ masyarakat pernah bertransaksi secara online baik barang maupun jasa. (www.apjii.or.id)

Selain melalui market place seperti bukalapak, olx, shoppee, lazada dan lain sebagainya, berbagai konten internet seperti facebook, twitter, instagram, whattsap juga tidak menutup kemungkinan dimanfaatkan individu dalam bertransaksi online.Hal inilah yang menjadikan masyarakat semakin tidak rasional dalam menggunakan sosial media. Mereka akan lebih sering berbelanja melalui online dibandingkan belanja secara langsung baik di mall maupun supermarket. Selain itu, banyak dari penjual online yang berani memasang harga lebih rendah dibandingkan harga pasaran.Mengapa terjadi hal seperti itu? Hal ini dikarenakan penjual online tersebut tidak perlu lagi menyewa "lapak" untuk bisa berjualan.Hanya melalui gadget dan sosial media mereka sudah mampu memperoleh penghasilan.Tanpa harus mengeluarkan modal besar untuk sewa tempat di mall/toko, para penjual online tidak perlu lagi membayar listrik, pajak dan lain sebagainya.

Hal seperti ini akan menimbulkan perilaku konsumtif terutama bagi generasi muda saat ini. Demi memenuhi gaya hidup mereka maka mereka 
akan memilih untuk membeli barang secara online yang notabene memiliki harga yang terjangkau dan lebih murah. Pentingnya sifat pengendalian diri dan memiliki pengelolaan keuangan yang baik akan membantu para generasi muda untuk tidak terjebak ke dalam perilaku konsumtif terutama ketika melakukan online shopping (belanja secara online).

Tujuan dari penelitian ini adalah untuk memprediksi dan menjelaskan bahwa life style, self control, dan financial literacy merupakan faktorfaktor yang memiliki pengaruh terhadap perilaku konsumtif mahasiswa dalam melakukan online shopping. Hasil penelitian diharapkan dapat menambah khasanah keilmuan terutama bagi para generasi muda atau mahasiswa agar tidak terjebak dengan perilaku konsumtif akibat pemenuhannya terhadap gayahidup. Pentingnya pengendalian diri dan pengelolaan keuangan yang baik sejak dini akan menghidarkan mereka dari perilaku yang cenderung konsumtif.

\section{Life Style}

Life style (gaya hidup) merupakan pola hidup seseorang di dunia yang diekspresikan dalam halaktivitas, minat, dan opininya (Kotler, 2007). Gaya hidup menggambarkan "keseluruhan diri seseorang" dalam berinteraksi dengan lingkungannya. Dapat disimpulkan bahwa gaya hidup merupakan pola hidup seseorang tentang bagaimana seseorang mampu mengalokasikan waktu maupun dalam hal membelanjakan uangnya dengan baik.

Pada hakikatnya perkembangan zaman dan teknologi berkaitan erat dengan gaya hidup. Perkembangan teknologi yang semakin canggih, akan menjadikan semakin berkembangnya penerapan gaya hidup oleh manusia terutama di dalam kehidupan sehari-hari. Dewasa ini, seringkali gaya hidup justru sering disalahgunakan oleh sebagian besar generasi muda terutama golongan mahasiswa yang berada dalam kota Metropolitan seperti di kota Surabaya. Para mahasiswa tersebut seringkali memiliki kecenderungan bergaya hidup dengan cara mengikuti mode yang lagi tren atau booming. Dapat dikatakan bahwa mereka cenderung lebih menyukai suatu pola hidup dimana yang aktivitasnya hanya bertujuan untuk mencari kesenangan. Seperti contohnya para generasi muda yang lebih banyak menghabiskan waktu diluar rumah, menyenangi keramaian kota, suka membeli barang hanya untuk mengikuti mode, serta selalu ingin menjadi pusat perhatian. Gaya hidup seperti inilah yang disebut dengan gaya hidup hedonis. Gaya hidup hedonis merupakan suatu gaya hidup yang dapat berupa penampilan baik melalui media iklan, modeling dari artis yang diidolakan sehingga menuntut mereka untuk dapat meniru para idolanya dengan cara mengikuti fashion dan mode.

\section{Self Control}

"Self control refers to one's ability control of override one's thoughts, emotions, urges, and behavior" (Gailliot, et al, 2007). Pengendalian diri mengacu pada kemampuan seorang individu dalam mengendalikan pikiran, emosi, tekanan bahkan perilaku seseorang.

Terdapat tiga aspek kemampuan dalam mengendalikan diri, yang biasanya disebut dengan kontrol personal (Ghufron dan Rini, 2011). Ketiga aspek tersebut adalah (1) behavioral control (kontrol perilaku), (2) cognitive control (kontrol kognitif), dan (3) decisional control (kontrol dalam pengambilan keputusan).

Selain ketiga aspek kemampuan dalam mengendalikan diri, terdapat pula dua faktor yang mampu mempengaruhi pengendalian diri, kedua faktor tersebut adalah faktor internal dan faktor eksternal (Ghufron dan Rini, 2011). Usia merupakan salah satu faktor internal yang memiliki andil terhadap kontrol diri seseorang. Dengan bertambahnya usia seseoranga maka semakin baik pula kemampuan dalam mengontrol diri. Sedangkan, lingkungan keluarga merupakan salah satu faktor yang memiliki andil pada faktor eksternal. Lingkungan keluarga terutama orangtua memiliki andil atau pengaruh besar dalam menentukan bagaimana seseorang memiliki kemampuan dalam mengontrol diri. Apabila orangtua mulai sejak dini telah menerapkan sikap disiplin kepada anaknya secara intens, maka sikap konsisten ini akan diinternalisasi oleh anak dan kemudian secara tidak langsung sikap disiplin tersebut akan menjadi kontrol diri bagi diri mereka sendiri.

\section{Literasi Keuangan}

"Financial literacy is the ability to make informed judgments and to take effective decisions regarding the use and management of money" (Bhushan and Medury, 2013). Literasi keuangan merupakan kemampuan dari setiap individu dalam membuat penilaian informasi serta mengambil keputusan secara efektif terhadap penggunaan dan pengelolaan dari setiap keuangan individu.

The Master Card Foundation's Report (2011) menyatakan bahwa tingkat literasi keuangan yang 
rendah dapat membuat seseorang sering mengambil keputusan keuangan yang tidak produktif, contohnya seperti menghabiskan uang untuk hal-hal yang kurang berguna, berutang terlalu banyak, menabung terlalusedikit sehingga kehilangan kesempatan untuk berinvestasi. Hal ini seiring dengan pernyataan dari Robb (dalam Putri dan Henny, 2017) yang menjelaskan bahwa pengetahuan akan literasi keuangan yang cukup dapat memberikan pengaruh yang positif terhadap perilaku keuangan, dengan demikian seseorang akan mampu mengatur atau mengalokasikan keuangannya dengan langkah yang tepat.

Kerangka Konseptual dan Hipotesis

Kerangka konseptual yang digunakan di dalam penelitian ini adalah:

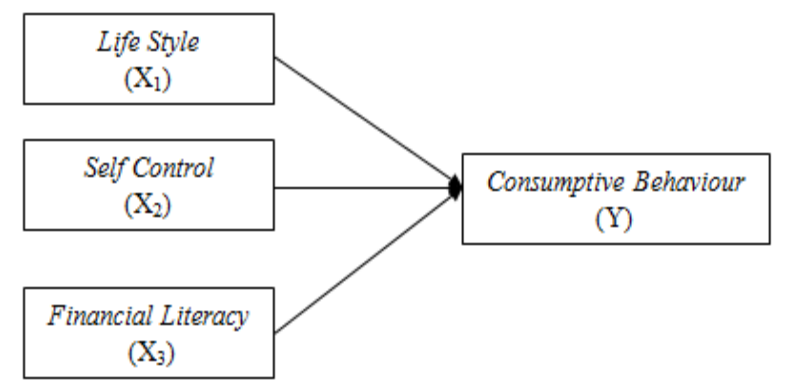

\section{Gambar 1 Kerangka Konseptual}

Berdasarkan kerangka konseptual di atas maka hipotesis yang digunakan di dalam penelitian ini adalah sebagai berikut:

$\mathrm{H} 1$ : Life stlye berpengaruh terhadap perilaku

konsumtif mahasiswa dalam melakukan online shopping.

H2: Self control berpengaruh terhadap perilaku konsumtif mahasiswa dalam melakukan online shopping.

H3: Financial literacy berpengaruh terhadap perilaku konsumtif mahasiswa dalam melakukan online shopping.

\section{METODE PENELITIAN}

Penelitian ini menggunakan metode penelitiankuantitatif melalui survei sehingga penelitian ini nantinya akanmenggunakan data primer. Metode survei digunakan untuk mendapatkan data dari tempat tertentu secara alamiah, penelitiakan melakukan beberapa perlakuan dalam pengumpulan data, yaitu dengan cara menyebarkan kuesioner, melakukan test maupun melakukan wawancara terstruktur (Sugiyono, 2014).

Subyek penelitian adalah mahasiswa fakultas ekonomi dan bisnis di perguruan tinggi atau sekolah tinggi yang ada di Kota Surabaya, Jawa Timur. Untuk mempermudah penelitian, peneliti memilih lokasi di wilayah Surabaya Timur, dimana di dalam wilayah tersebut ada beberapa universitas yang dipilih peneliti yaitu UPN (Universitas Pembangunan Nasional), Universitas 17 Agustus 1945, Universitas Dr. Soetomo, Universitas Narotama, Universitas Wr. Soepratman, STIESIA, STIE Perbanas. Pemilihan ini berdasarkan pada wilayah geografis, dimana universitas tersebut juga memiliki Fakultas Ekonomi dan Bisnis. Tujuan pemilihan ini adalah untuk memudahkan penelitian.

Target populasi yang digunakan dalam penelitian ini adalah seluruh mahasiswa fakultas ekonomi dan bisnis yang kuliah di Perguruan Tinggi di Surabaya diutamakan mahasiswa yang sering memanfaatkan social media baik untuk berkomunikasi, bertransaksi jual beli dan sebagainya. Karena populasi yang digunakan di dalam penelitian ini adalah seluruh mahasiswa di fakultas ekonomi dan bisnis wilayah kota Surabaya Timur maka jumlahnya tidak diketahui pasti sehingga disebut sebagai populasi infinite (tak terhingga). Maka pengambilan sampel dilakukan dengan cara menggunakan rumus sebagai berikut:

$$
n=\frac{([Z \propto])^{2} \times(p \times q)}{d^{2}}
$$

\section{Dimana:}

$$
\begin{aligned}
\mathrm{n}= & \text { Besar sampel } \\
\mathrm{p}= & \text { Estimator proporsi populasi } \\
& \text { (jika tidak diketahui } \\
& \text { dianggap } 50 \%=0,5) \\
\mathrm{q}= & 1-\mathrm{p}(100 \%-\mathrm{p}) \\
\mathrm{Z} \alpha^{2}= & \text { Harga kurva normal yang } \\
& \text { tergantung dari alpha } \\
& (\text { Za0.05 = 1,96) } \\
\mathrm{d}= & \text { Toleransi kesalahan yang } \\
& \text { dipilih, menggunakan batas } \\
& \text { kesalahan sebesar 10\% }(\mathrm{d}= \\
& \text { 0.1) yang berarti tingkat } \\
& \text { akurasi sebesar } 90 \% .
\end{aligned}
$$

Dengan menggunakan rumus di atas maka diperoleh jumlah sampel minimal sebanyak 96 responden.

Instrumen penelitian ini adalah kuesioner dengan pengukuran variabel yang menggunakan "Skala Likert".Skala likert digunakan untuk 
mengukur sikap ataupun respon dari seseorang terhadap suatu objek yang akan diteliti. Jawaban responden atas pertanyaan atau pernyataan tersebut berupa pemilihan jawaban "setuju" hingga "tidak setuju". Pada penelitian ini skala likert yang akan digunakan adalah sebagai berikut:

\section{Tabel 1}

\section{Pengukuran Variabel}

\begin{tabular}{cc}
\hline Sangat Tidak Sesuai (STS) & 1 \\
\hline Tidak Sesuai (TS) & 2 \\
\hline Ragu - Ragu (R) & 3 \\
\hline Sesuai (S) & 4 \\
\hline Sangat Sesuai (SS) & 5 \\
\hline
\end{tabular}

Variabel yang digunakan di dalam penelitian ini adalah:

Variabel independen $(\mathrm{X})$ yang meliputi:

\section{Life Style $\left(\mathrm{X}_{1}\right)$}

Variabel life style menggambarkan perilaku seseorang tentang bagaimana dia hidup, menggunakan uang dan memanfaatkan waktu yang dimiliki dalam aktivitas, minat serta opininya.Tujuannya adalah untuk menambah kepercayaan diri dalam pergaulan dan menjadi penilaian status sosial. Indikator-indikator lifestyle meliputi kepercayaan diri, koleksi, status sosial dan hobi (Kotler, 2007).

\section{Self Control $\left(\mathrm{X}_{2}\right)$}

Variabel self control merupakan suatu aktivitas pengendalian tingkah laku yang berkaitan dengan bagaimana individu mengendalikan emosi serta dorongan dari dalam dirinya agar mengarah pada perilaku yang positif. Indikator dalam mengukur self control meliputi kemampuan mengontrol perilaku, mengontrol stimulus, mengantisipasi suatu peristiwa atau kejadian, menafsirkan peristiwa atau kejadian dan pengambilan keputusan (Ghufron dan Rini, 2014

\section{Literasi Keuangan $\left(\mathrm{X}_{3}\right)$}

Variabel literasi keuangan diukur dengan empat indikator menurut yaitu uang dan transaksi, perencanaan dan pengelolaan keuangan, risiko dan keuntungan serta financial landscape (OECD, 2012). Instrumen yang digunakan merupakan pengembangan kuesioner yang disusun oleh Mandell (2008).

Variabel dependent $(\mathrm{Y})$ yang meliputi:

Consumptive Behaviour (Y)
Perilaku pembelian impulsif merupakan perilaku membeli tanpa ada perencanaan, terjadi secara tiba-tiba dan keinginan yang kuat untuk membeli dengan segera tanpa ada pertimbangan terlebih dahulu.Variabel ini diukur dengan indikator yang mengacu pada karakteristik yaitu, spontanitas (spontaneity); kekuatan, kompulsi dan intensitas (power, compulsion and intensity); kegairahan dan stimulasi (excitement and stimulation); dan ketidakpedulian akan akibat (disregard for consequences) (Febyanti, 2006)

\section{Teknik Analisis}

Peneliti menggunakan analisis regresi berganda untuk meneliti pengaruh life style, self control dan literasi keuangan terhadap perilaku konsumtif pembelian secara online pada mahasiswa fakultas ekonomi dan bisnis di wilayah Surabaya Timur. Proses pengolahan data menggunakan program SPSS.Tahapan yang dilalui meliputi analisis statistik deskriptif, uji validitas, uji reliabilitas, uji normalitas dan uji regresi linear berganda. Persamaan regresi linier berganda di dalam penelitian ini dapat dituliskan sebagai berikut:

$$
\mathrm{Y}=\alpha \_0+\alpha \_1 \mathrm{X} \_1+\alpha \_2 \mathrm{X} \_2+\alpha \_3 \mathrm{X} \_3+\varepsilon
$$

Dimana,

$\mathrm{Y}=$ Perilaku konsumtif

$\mathrm{X} 1=$ Life Style

$\mathrm{X} 2=$ Self Control

$\mathrm{X} 3=$ Literasi Keuangan

\section{Pengujian Hipotesis}

Uji $t$ dalam regresi linier berganda dimaksudkan untuk menguji apakah parameter (koefisien regresi dan konstanta). Dengan menggunakan uji t maka dapat dengan mudah ditarik kesimpulan yaitu apabila nilai prob. t hitung (ouput SPSS ditunjukkan pada kolom sig.) lebih kecil dari tingkat kesalahan/error (alpha) maka dapat dikatakan bahwa variabel independen berpengaruh signifikan terhadap variabel dependen begitu sebaliknya.

\section{PEMBAHASAN \\ Uji Analisis Deskriptif}

Deskripsi data memberikan gambaran umum mengenai hasil penyebaran kuesioner. Berikut adalah rincian penyebaran dan tingkat pengembalian kuesioner: 
Tabel 2

Tingkat Pengembalian Kuesioner

\begin{tabular}{lc}
\hline \multicolumn{1}{c}{ Kuesioner } & Jumlah \\
\hline Kuesioner yang disebar & 120 \\
\hline Kuesioner yang tidak kembali & 7 \\
\hline Kuesioner yang tidak digunakan & 10 \\
\hline Kuesioner yang digunakan & 102 \\
\hline Sumber: Data diolah &
\end{tabular}

Tabel 3

Analisis Deskriptif

\begin{tabular}{|c|c|c|}
\hline $\begin{array}{c}\text { Data Responden } \\
\text { Berdasarkan }\end{array}$ & Kriteria & $\begin{array}{c}\text { Presentase } \\
(\%)\end{array}$ \\
\hline \multirow{2}{*}{ Jenis Kelamin } & Laki-laki & 26,5 \\
\hline & Perempuan & 73,5 \\
\hline \multirow{4}{*}{ Usia } & 17-21 thn & 19,6 \\
\hline & $22-26$ thn & 47,1 \\
\hline & $27-31$ thn & 31,4 \\
\hline & $>31$ thn & 2 \\
\hline \multirow{3}{*}{$\begin{array}{l}\text { Pendapatan / Uang } \\
\text { Saku per bulan }\end{array}$} & $<2$ juta & 32,4 \\
\hline & 2-3 juta & 51 \\
\hline & $>3$ juta & 16,7 \\
\hline \multirow{4}{*}{$\begin{array}{l}\text { Lamanya } \\
\text { memanfaatkan } \\
\text { sosmed }\end{array}$} & $<2$ jam & 6,9 \\
\hline & $2-5$ jam & 36,3 \\
\hline & 5-8 jam & 30,4 \\
\hline & $>8$ jam & 26,5 \\
\hline \multirow{4}{*}{$\begin{array}{l}\text { Tujuan } \\
\text { pemanfaatan } \\
\text { sosmed }\end{array}$} & $\begin{array}{c}\text { Sosial } \\
\text { Network }\end{array}$ & 23,5 \\
\hline & $\begin{array}{l}\text { Jual Beli } \\
\text { Online }\end{array}$ & 55,9 \\
\hline & $\begin{array}{c}\text { Layanan } \\
\text { surel }\end{array}$ & 4,9 \\
\hline & Google & 15,7 \\
\hline
\end{tabular}

Sumber: Data diolah

\section{Uji Validitas dan Reliabilitas}

Dalam penelitian ini data yang diuji sebanyak 102 dengan menggunakan software SPSS 21. for windows. Item atau indikator dikatakan valid jika hasil angka korelasi product moment Pearson $(\mathrm{r}$ hitung) pada level signifikansi $<0,01$ dan suatu instrumen di dalam penelitiandapat dikatakan valid jika nilai koefisien korelasinya lebih besar dari 0.3. Hasil pengujian validitas ditunjukkan pada tabel sebagai berikut:

Tabel 4 menunjukkan bahwa item-item pertanyaan pada variabel independen yaitu life style $\left(\mathrm{X}_{1}\right)$, self control $\left(\mathrm{X}_{2}\right)$, literasi keuangan $\left(\mathrm{X}_{3}\right)$ dan variabel dependen yaitu consumptive behaviour (y) menunjukkan bahwa seluruh item pertanyaan pada variabel independen dan dependen mempunyai nilai $r$ yang lebih besar dari 0.3 ( $\mathrm{r}>0.3$ ) dan mempunyai nilai probabilitas lebih kecil dari $0,01(\alpha<0.01)$ sehingga dinyatakan bahwa data yang dihasilkan adalah "valid".

Tabel 4

Hasil Uji Validitas

\begin{tabular}{|c|c|c|c|c|}
\hline Variabel & $\begin{array}{l}\text { Indikator } \\
\text { Item }\end{array}$ & $\begin{array}{c}\text { Koefisien } \\
\text { Korelasi }\end{array}$ & Sig. & Ket. \\
\hline \multirow{5}{*}{$\begin{array}{l}\text { Life Style } \\
\qquad\left(\mathrm{X}_{1}\right)\end{array}$} & $\mathrm{X}_{1.1}$ & 0.727 & 0.000 & Valid \\
\hline & $\mathrm{X}_{1.2}$ & 0.762 & 0.000 & Valid \\
\hline & $\mathrm{X}_{1.3}$ & 0.705 & 0.000 & Valid \\
\hline & $\mathrm{X}_{1.4}$ & 0.648 & 0.000 & Valid \\
\hline & $\mathrm{X}_{1.5}$ & 0.604 & 0.000 & Valid \\
\hline \multirow{5}{*}{$\begin{array}{c}\text { Self } \\
\text { Control } \\
\left(\mathrm{X}_{2}\right)\end{array}$} & $\mathrm{X}_{2.1}$ & 0.897 & 0.000 & Valid \\
\hline & $\mathrm{X}_{2.2}$ & 0.870 & 0.000 & Valid \\
\hline & $\mathrm{X}_{2.3}$ & 0.896 & 0.000 & Valid \\
\hline & $\mathrm{X}_{2.4}$ & 0.906 & 0.000 & Valid \\
\hline & $\mathrm{X}_{2.5}$ & 0.894 & 0.000 & Valid \\
\hline \multirow{5}{*}{$\begin{array}{l}\text { Literasi } \\
\text { Keuangan } \\
\quad\left(\mathrm{X}_{3}\right)\end{array}$} & $X_{3.1}$ & 0.854 & 0.000 & Valid \\
\hline & $\mathrm{X}_{3.2}$ & 0.801 & 0.000 & Valid \\
\hline & $X_{3.3}$ & 0.819 & 0.000 & Valid \\
\hline & $\mathrm{X}_{3.4}$ & 0.854 & 0.000 & Valid \\
\hline & $X_{3.5}$ & 0.832 & 0.000 & Valid \\
\hline \multirow{7}{*}{$\begin{array}{l}\text { Consump- } \\
\text { tive } \\
\text { Behavi- } \\
\text { our }(\mathrm{Y})\end{array}$} & $\mathrm{Y}_{1.1}$ & 0.543 & 0.000 & Valid \\
\hline & $\mathrm{Y}_{1.2}$ & 0.722 & 0.000 & Valid \\
\hline & $Y_{1.3}$ & 0.726 & 0.000 & Valid \\
\hline & $\mathrm{Y}_{1.4}$ & 0.723 & 0.000 & Valid \\
\hline & $Y_{1.5}$ & 0.716 & 0.000 & Valid \\
\hline & $Y_{1.6}$ & 0.769 & 0.000 & Valid \\
\hline & $Y_{1.7}$ & 0.535 & 0.000 & Valid \\
\hline
\end{tabular}

Sumber: Data diolah

Tabel 5

Hasil Uji Reliabilitas

\begin{tabular}{lcc}
\hline \multicolumn{1}{c}{ Variabel } & $\begin{array}{c}\text { Reliabilitas } \\
\text { (Cronbach's Alpha) }\end{array}$ & Ket \\
\hline Life Style $\left(\mathrm{X}_{1}\right)$ & 0.726 & Reliabel \\
\hline Self Control $\left(\mathrm{X}_{2}\right)$ & 0.936 & Reliabel \\
\hline $\begin{array}{l}\text { Financial } \\
\text { Literacy }\left(\mathrm{X}_{3}\right)\end{array}$ & 0.888 & Reliabel \\
\hline $\begin{array}{l}\text { Consumptive } \\
\text { Behaviour }(\mathrm{Y})\end{array}$ & 0.803 & Reliabel \\
\hline Sumber: Data diolah & & \\
\hline
\end{tabular}

Sumber: Data diolah

Tabel 5 menunjukkan bahwa koefisien cronbach's alpha pada semua item pertanyaan untuk variabel independen (life style $\left(\mathrm{X}_{1}\right)$, self control $\left(\mathrm{X}_{2}\right)$, literasi keuangan $\left(\mathrm{X}_{3}\right)$ ) dan dependen (consumptive behaviour (Y)) seluruhnya menunjukkan nilai lebih dari 0,60. Dengan demikian seluruh variabel baik independen 
maupun dependen dinyatakan memiliki reliabilitas / kehandalan yang baik atau "reliabel".

\section{Uji Regresi Linier Berganda}

\begin{tabular}{lcccc}
\multicolumn{7}{c}{ Tabel 6} \\
\multicolumn{1}{c}{ Hasil Uji Regresi Linear } & & \\
\multicolumn{1}{c}{ Variabel } & $\begin{array}{c}\text { Koef. } \\
\text { Reg }\end{array}$ & t-hitung & Sign & Ket \\
& 22.431 & 8.018 & 0.000 & \\
\hline Konstanta & 0.496 & 3.780 & 0.000 & $\begin{array}{c}\text { Positif } \\
\text { Signifikan }\end{array}$ \\
\hline Life Style $\left(\mathrm{X}_{1}\right)$ & & & & $\begin{array}{c}\text { Negatif } \\
\text { Signifikan }\end{array}$ \\
\hline $\begin{array}{l}\text { Self Control } \\
\left(\mathrm{X}_{2}\right)\end{array}$ & -0.214 & -3.098 & 0.003 & $\begin{array}{c}\text { Negatif } \\
\text { Signifikan }\end{array}$ \\
\hline $\begin{array}{l}\text { Financial } \\
\text { Literacy }\left(\mathrm{X}_{3}\right)\end{array}$ & -0.198 & -2.135 & 0.035 & \\
\hline $\begin{array}{l}\text { R Square }=0.181 \\
\text { F Hitung }=7.237 \\
\text { N dengan Sign. } 0.000\end{array}$ & & & \\
\hline Sumber: Data diolah & & & \\
\hline
\end{tabular}

Sumber: Data diolah

Keterangan :

Variabel Dependen : Consumptive Behaviour

Signifikan pada level 5\%

Berdasarkan tabel 6 maka diperoleh persamaan model regresi adalah sebagai berikut ini $\mathrm{Y}=22.431+0.496 \mathrm{X}_{1}-0.214 \mathrm{X}_{2}-0.198 \mathrm{X}_{3}+\varepsilon$

\section{Pengujian Hipotesis}

Pengujian hipotesis di dalam penelitian ini menggunakan Uji t. Uji t digunakan untuk menguji apakah terdapat pengaruh variabel independen terhadap variabel dependen. Berdasarkan hasil perhitungan maka dapat diketahui apakah variabel life style, self control literasi keuangan berpengaruh terhadap consumptive behaviour hasil perhitungan dapat ditunjukkan pada tabel berikut ini.

\section{Tabel 7}

\section{Hasil Perhitungan Pengujian Hipotesis}

\begin{tabular}{cccc}
\hline Variabel & t hitung & Sign. & Hasil Hipotesis \\
\hline Life style & 3.780 & 0.000 & $\mathrm{H}_{1}$ diterima \\
\hline Self Control & -3.098 & 0.003 & $\mathrm{H}_{2}$ diterima \\
\hline $\begin{array}{c}\text { Financial } \\
\text { Literacy }\end{array}$ & -2.135 & 0.035 & $\mathrm{H}_{3}$ diterima \\
\hline
\end{tabular}

Sumber: Data diolah

Pengaruh Life Style Terhadap Consumptive Behaviour

Berdasarkan hasil perhitungan yang ditunjukkan pada Tabel 7 diperoleh bahwa nilai tstatistik sebesar 3.780 dan nilai sig. 0.000. Nilai ini memperlihatkan bahwa nilai probabilitas nilai $\mathrm{t}$ atau signifikan lebih kecil 5\% (0.000 < 0.05$)$. Dengan demikian pengujian tersebut menunjukkan bahwa H1 diterima. Berdasarkan tabel 6 menunjukkan bahwa nilai koef. Reg $(\beta=0.496)$, hasil ini memperlihatkan bahwa variabel life style (gaya hidup) berpengaruh secara positif dan signifikan terhadap consumptive behaviour (perilaku konsumtif).

Hasil pengujian ini didukung oleh penelitian sebelumnya yaitu yang menemukan bahwa market place mampu mempengaruhi life style dari kalangan mahasiswa (Desty, 2017) Dengan adanya marketplace tersebut maka mahasiswa berperilaku konsumtif dalam melakukan online shopping. Gaya hidup adalah cara hidup seseorang yang menghabiskan waktu dan daya guna uang (James dkk, 2015). Gaya hidup dapat diamati melalui aktivitas, minat dan opini yang dilakukan oleh mahasiswa. Apabila perilaku konsumtif tersebut terus dilakukan tanpa adanya pemikiran panjang maka akan berakibat terjadinya tindakan pemborosan dimana seseorang tidak akan dapat membedakan mana yang benar-benar dibutuhkan dan mana yang hanya sekedar keinginan semata.

Pengaruh Self Control Terhadap Consumptive Behaviour

Berdasarkan hasil perhitungan yang ditunjukkan pada Tabel 7 diperoleh bahwa nilai tstatistik sebesar -3.098 dan nilai sig. 0.003. Nilai ini memperlihatkan bahwa nilai probabilitas nilai $\mathrm{t}$ atau signifikan lebih kecil 5\% (0.003<0.05). Dengan demikian pengujian tersebut menunjukkan bahwa $\mathrm{H} 2$ diterima. Berdasarkan tabel 6 menunjukkan bahwa nilai koef. Reg $(\beta=-0.214)$, hasil ini memperlihatkan bahwa variabel self control (pengendalian diri) berpengaruh secara negatif dan signifikan terhadap consumptive behaviour (perilaku konsumtif).

Hasil pengujian ini didukung oleh penelitian sebelumnya, menurut Sharma, dkk (2013) perilaku konsumtif memiliki hubungan dengan devisit kontrol diri dengan kata lain apabila kontrol diri tinggi maka tidak akan terjadi perilaku konsumtif, sebaliknya rendahnya kontrol diri seseorang akan menyebabkan orang tersebut berperilaku konsumtif. perilaku konsumtif dapat ditekan dan bahkan dihindari apabila seseorang memiliki sistem pengendalian internal padadirinya yang disebut kontrol diri. Selain itu masalah kontrol diri merupakan masalah yang dilibatkan proses belajar pengendalian diri untuk menurunkan perilaku eksesif yang memberi kepuasan segera. Pengaruh 


\section{Literasi Keuangan Terhadap Consumptive Behaviour}

Berdasarkan hasil perhitungan yang ditunjukkan pada Tabel 7 diperoleh bahwa nilai tstatistik sebesar -2.135 dan nilai sig. 0.035. Nilai ini memperlihatkan bahwa nilai probabilitas nilai $\mathrm{t}$ atau signifikan lebih kecil 5\% (0.035 < 0.05$)$. Dengan demikian pengujian tersebut menunjukkan bahwa H3 diterima. Berdasarkan tabel 6 menunjukkan bahwa nilai koef. Reg $(\beta=-0.198)$, hasil ini memperlihatkan bahwa variabel literasi keuangan berpengaruh secara negatif dan signifikan terhadap consumptive behaviour (perilaku konsumtif).

Hasil pengujian didukung oleh penelitian sebelumnya yang menyatakan bahwa literasi keuangan merupakan kemampuan individu untuk mengambil keputusan dalam hal pengaturan keuangan pribadinya dituliskan oleh (Margaretha $\mathrm{dkk}, 2015)$. Jika seorang individu tidak mampu mengatur keuangan pribadinya maka dirinya akan terjebak pula dalam perilaku konsumtif terutama di era teknologi saat ini. Tersebarnya marketplace seperti Tokopedia, Lazada, Blibli, OLX dan lain sebagainya menjadikan mahasiswa mudah tergiur dengan berbagai promo yang diberikan.

Dalam penelitian Imawati, Susilaningsih dan Elvia (2013) juga dijelaskan bahwa materi pembelajaran yang diperoleh siswa di sekolah belum mampu diaplikasikan secara maksimal. Mahasiswa telah mendapatkan pembelajaran dari mata kuliah terkait pengelolaan keuangan namun mereka belum dapat mengaplikasikan teori pembelajaran tersebut secara maksimal. Hal ini dikarenakan selama pembelajaran, materi yang terkait pengelolaan keuangan seperti manajemen keuangan dan akuntansi manajemen lebih ditekankan pada aspek keperluan entitas sehingga mahasiswa masih sulit mengaplikasikan materi tersebut secara menyeluruh dalam pengelolaan keuangannya.

\section{PENUTUP}

\section{Kesimpulan}

Penelitian ini bertujuan untuk mengetahui apakah terdapat pengaruh life style, self control dan financial literacy terhadap consumptive behaviour. Berdasarkan hasil analisis yang telah dilakukan maka dapat disimpulkan bahwa:

1. Life style (gaya hidup) berpengaruh secara positif dan signifikan terhadap consumptive behaviour (perilaku konsumtif).
2. Self control (pengendalian diri) berpengaruh secara negatif dan signifikan terhadap consumptive behaviour (perilaku konsumtif).

3. Literasi keuangan berpengaruh secara negatif dan signifikan terhadap consumptive behaviour (perilaku konsumtif).

\section{Implikasi Manajerial}

Gaya hidup yang dimiliki oleh mahasiswa yang kuliah di fakultas ekonomi dan bisnis di Surabaya khususnya wilayah Surabaya timur mempunyai pengaruh terhadap perilaku konsumtif. Dapat dikatakan bahwa semakin tinggi life style maka semakin tinggi tingkatperilaku konsumtifnya, begitu pulasebaliknya. Berdasarkan hasil analisis dapat disimpulkan bahwa mahasiswa yang kuliah di fakultas ekonomi dan bisnis di Surabaya khususnya wilayah Surabaya timur cenderung berperilaku konsumtif dikarenakan dipengaruhi oleh life style mereka. Mereka cenderung membeli berdasarkan keinginan (agar mampu mengikuti mode-mode terbaru) dibandingkan dengan kebutuhan terutama ketika melakukan online shopping.Untuk dapat memenuhi life style, mereka lebih sering membeli secara online karena adanya faktor harga yang cenderung lebih murah dan sesuai dengan kantong mahasiswa. Hal tersebut yang menjadikan mahasiswa lebih mementingkan life style agar tak ketinggalan zaman dibandingkan kebutuhan mereka sebenarnya.

Tingkat pengendalian diri yang dimiliki oleh mahasiswa yang kuliah di fakultas ekonomi dan bisnis di Surabaya khususnya wilayah Surabaya timur mempunyai pengaruh terhadap perilaku konsumtif. Dapat dikatakan bahwa semakin tinggi self control maka semakin rendah tingkat perilaku konsumtifnya, begitu pulasebaliknya. Berdasarkan hasil analisis yang telah dilakukan dapat disimpulkan bahwa mahasiswa tersebut masih memiliki tingkat pengendalian diri yang kurang sehingga mereka cenderung berperilaku konsumtif terutama ketika melakukan online shopping.

Literasi keuangan yang berkaitan dengan pengelolaan keuangan yang dimiliki oleh mahasiswa yang kuliah di fakultas ekonomi dan bisnis di Surabaya khususnya wilayah Surabaya timur mempunyai pengaruh terhadap perilaku konsumtif. Semakin tinggi financial literacy yang mereka miliki maka semakin rendah tingkat perilaku konsumtifnya, begitu pula sebaliknya. Akan tetapi, berdasarkan hasil analisis yang telah dilakukan dapat disimpulkan bahwa mahasiswa 
yang kuliah di fakultas ekonomi dan bisnis di Surabaya khususnya wilayah Surabaya timur cenderung tidak mampu mengelola keuangannya secara pribadi sehingga pada akhirnya mereka terjebak pada perilaku konsumtif terutama ketika melakukan online shopping.

\section{Rekomendasi}

Pada penelitian ini, penulis menyadari masih terdapat banyak kekurangan-kekurangan dan keterbatasan. Pada penelitian ini, penulis hanya memandang faktor life style, self control dan financial literacy yang memiliki pengaruh terhadap consumptive behaviour. Berdasarkan hasil analisis diketahui pula bahwa konstribusi yang diberikan oleh ketiga variabel tersebut sangatlah sedikit. Sehingga, penelitian ini perlu dikembangkan lebih jauh lagi dengan menambahkan faktor-faktor lainnya yang diprediksi mampu memberikan pengaruh terhadap perilaku konsumtif.

\section{DAFTAR PUSTAKA}

Bhushan, P. and Medury, Y. 2013. Financial Literacy and its Determinants. International Journal of Engineering, Business and Enterprise Applications (IJEBEA), 4(2),155160.

Febyanti, Riza. 2016. Perilaku Konsumtif Remaja Ditinjau dari Gaya Hidup Hedonis dan Tipe Kepribadian Extravert Introvert. Universitas Gajah Mada. Yogyakarta: Thesis.

Gailliot, M. T., Baumeister, R. F., Dewall, C. N., Maner, J. K., Plant, E. A., Tice, D. M., Brewer, L. E. \& Schmeichel, B. J. 2007. Self Control Relies on Glucose as Limited Energy Source: Willpower is Niore Then a Metaphor. Journal of Personality and Social Psychology, 92(2) : 325-336.

Imawati, I., Susilaningsih, dan Elvia, I. 2013. Pengaruh Financial Literacy terhadap Perilaku Konsumtif Remaja pada Program IPS SMA Negeri 1 Surakarta Tahun Ajaran 2012/2013. Jupe UNS, Vol 2 No. 1 Hal. 48 s/d 58.
James F.Engel \& Roger D.Blackwell \& Paul W. Miniard, F. X. Budiyanto. 2015. Perilaku Konsumen. Jakarta: Binarupa Aksara.

Kotler, Philip \& Armstong, Gary. 2007. PrinsipPrinsip Pemasaran Edisi Keduabelas Jilid 1. Alih bahasa: Bob Sabran. Jakarta: Erlangga.

Mandell, Lewis. 2008. The Financial Literacy of Young American Adult. Result of The National Jumpstart Coalition Survey of High Scholl Seniors and College Student. The Jumpstart Coalition for Personal Financial Leteracy: Washington.

Margaretha, Farah dan Pambudhi, Reza Arief. 2015. Tingkat Literasi Keuangan pada Mahasiswa S-1 Fakultas Ekonomi. Jurnal Manajemen dan Kewirausahaan. Vol. 17 No.17: 76-85.

Ghufron, M. Nur. dan Rini, Risnawati. 2014. Teori-Teori Psikologi. Yogjakarta: Ar- Ruzz Media.

Organization for Economic Cooperation and Development (OECD), Program for International Student Assessment (PISA). 2012. Financial Literacy Assesment Freamwork. Amerika: International Network on Financial Education.

Putri, N.M.D.R dan Henny, R. 2017. Pengaruh Tingkat Literasi Keuangan dan Faktor Sosiodemografi terhadap Perilaku Keputusan Investasi Individu. E-Jurnal Ekonomi dan Bisnis Universitas Udayana.

Sharma, P., Sivakumaran, B. \& Marshall. R. .2013. Looking Beyond Impulse Buying A CrossCultural And Multi-Domain Investigation Of Consumer Impulsiveness. European Journal of Marketing. 48 (5). 11591179.

Sugiyono. 2014. Metode Penilaian Kuantitatif, Kualitatif dan $R \& D$. Penerbit Alfabeta: Bandung.

https://www.apjii.or.id 